InVisible Culture • Issue 31: Black Studies Now and the CounterCurrents of Hazel Carby

\title{
Get Down: Funk, \\ Movement, and the End of \\ the Great Migrations
}

Patrick Sullivan ${ }^{1}$

${ }^{1}$ University of Rochester

Published on: Nov 15, 2020

DOI: $10.47761 / 494 a 02 f 6.685234 b 4$

License: Creative Commons Attribution 4.0 International License (CC-BY 4.0). 


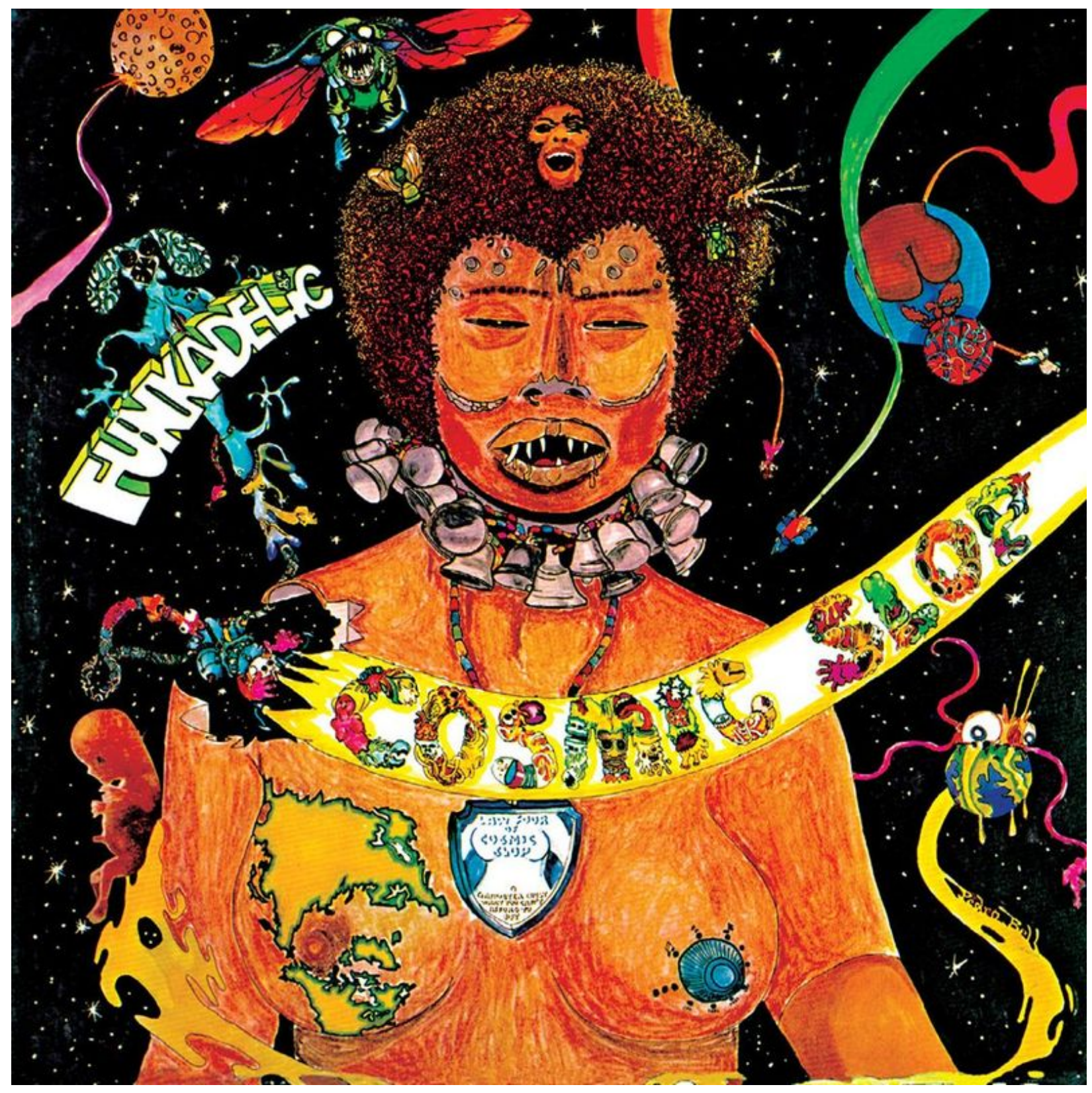

Funk is neither an essence nor a Black metaphysics but rather should be seen as a complex musical and aesthetic form that was created by Black artists to respond to and mediate Black experience at the end of the Great Migrations (1916-1970). Beginning in the early twentieth century and lasting through the postwar period, waves of migrating Black people left the South to urban centers of the North and West Coast, fleeing racism and pursuing economic opportunities. Their movement changed the demographic landscape of the United States. By the 1960s, this social movement began to wane. The promises of mobility were short lived. Black Americans who had 
come to northern and western cities faced racist economic structures: White flight, deindustrialization, limited community and educational resources, and the decimation of urban neighborhoods through expansion of the highway system. The decade's series of riots index the social and economic disparity that Black Americans endured. Cities that once offered dreams of freedom became nightmares of social constraint. The end of the Great Migrations embodies a moment of spatial constriction.

With the end of the Great Migrations, funk offered modes of aesthetic and imaginative movement. Funk was the music of a generation, a generation that as children took part in the migrations, and in their teen years had been part of prior Black musical genres: soul, blues, and jazz. In the middle of the 1960s, shortly after the Watts riots, funk erupted onto the national music scene with James Brown's "Papa's Got a Brand New Bag." Soon after, funk began to flood out of cities: Chicago, Dayton, Detroit, Memphis, San Francisco; it was an urban music (born in New Orleans) that fused prior Black musical genres to put emphasis on musical movement, movement often overtly referenced in the lyrics. By the late 1960s, other Black artists were leaning towards funk music: Sly and the Family Stone, The Isley Brothers, The Parliaments, and The Ohio Players, to name a few. Like James Brown, many funk bands started out in other musical genres and transitioned to the genre through the late 1960s. By the 1970s, funk's characteristics began to dominate the music of Black popular culture.

Historically, funk developed in tandem with the social structure of the end of the Great Migrations and, in many ways, should be seen as its sonic relief. It is a cultural form all about moving when social and economic mobility was winding down.

It is the argument of this essay that funk's aesthetic, one centered on the production of movement, registers the dwindling of movement in social life and that this registering is articulated around gender, that is, the figure of the Black woman occupies a central place in funk's imaginative movement. This is unsurprising, for while Black women's migration caught up to Black men's migration during the 1960s, the economic reality existing at the end of the Great Migrations differed for men and women. The existence of Black women in urban spaces has long generated social and political anxiety. 1 The end of the Great Migrations was no different. The body of the urban Black woman magnetizes fears around uncontrolled and unbridled Black female sexuality, social degradation, miscegenation, and women's independence. A common figure of this constellation is the prostitute or streetwalker, who regularly appears in funk music. Funk vectored Black women and their sexuality towards an articulation of movement. 
In taking up funk as an aesthetic mediation of a historical period of Black experience in the United States, I am pushing back against notions of funk as related to essence, authenticity, or any other verbiage that might trace its core back to ontology. $\underline{2}$ Tony Bolden, a funk music scholar, criticizes such localizations of funk and Black aesthetics in innate-ness. For Bolden, the positioning of Black performance as innate rather than learned (that is, as a product of craft, discipline, technē, and ultimately, intelligence, even if claiming to be liberatory) places Black people as underdeveloped. $\underline{3}$ Instead of offering metaphysical/mythical origin for funk, he suggests that it is an aesthetic inflection of cultural-economic life of Black Americans in the postwar era. He characterizes the aesthetic of funk as "speed, self-reflexivity, asymmetry, dissonance, and repetition." Indeed, drawing out the energetic valences of these qualities that he prescribes to funk, Bolden calls funk a "kinetic epistemology." Funk music was all about movement, producing a dynamism that prompted people to get down, groove, and dance. It erupted onto the national stage at the moment the promises of movement embodied in the Great Migrations were beginning to ring false.

\section{Funk's Cosmology}

Funk music explicitly reflected on the economic and social constraint that Black life was experiencing at the end of the Great Migrations. For instance, in 1972, War released the single "The World is a Ghetto." The title invokes the ghetto as a symbol of economic and social stagnation wrought by race in US urban locales. The first verse expresses a man's dissatisfaction with his current life: "Walkin' down the street, smoggy-eyed, Looking at the sky, starry-eyed, Searchin' for the place, weary-eyed, Crying in the night, teary-eyed." From this bluesy-rock verse, the song switches to a funk chorus with the lyrics, “Don't you know that it's true, That for me and for you, The world is a ghetto." The song then switches back to the bluesy-rock verse and expresses a desire for paradise: “Wonder when I'll find paradise, Somewhere there's a home sweet and nice, Wonder if I'll find happiness, Never give it up now I guess." The funk picks up and meets the desire of the verse with the chorus: "The world is a ghetto." On the final verse, the singer has come to think "There's no need to search anywhere, Happiness is here, have your share, If you know you're loved, be secure, Paradise is love to be sure." In a perfect pop cop-out, love serves as paradise in the ghetto. This funk song's lyrics directly sublimate political change into vaguely romantic satisfaction. But this is hardly notable. After all, funk is pop, and one should not expect a pop song to address the structural oppression of what the ghetto is in any sustained meaningful way-can pop's form even handle such ideological work? $\stackrel{4}{4}$ What is of note here is the juxtaposition between the music of the verse and chorus and the lyrics that 
accompany each section. The narrative of the blues-rock verses tells a story of dissatisfaction, a longing for paradise, and acceptance of one's position. Conversely, the funk section asserts the conditions Black Americans were experiencing, life in the ghetto and the economic and social immobility it expresses. This assertion is accompanied by the rhythmic and tonal complexity of funk music. The funk chorus energizes the song and produces a tension with lyrics that signal social and economic stasis. While the blues-rock verses offer a trajectory, the chorus does not offer such synthesis. Lyrical and musical expressions of movement conflict and are held in tension. Such tension is noteworthy, for often in funk music and lyrics work in tandem to produce movement, conveying a sense of economic, sexual, political, and/or spatial freedom.

This desire for movement might reach its zenith in the commercially successful and critically praised funk of George Clinton and his brand of funk known as P-Funk. The brainchild of Clinton, P-Funk blends funk with rock and psychedelic music. This musical concoction is accompanied by lyrics that mix afro-futurism, nonsense, and cultural references. The P-Funk collective was made up of the bands Parliament, Funkadelic, and various side projects of the members. Clinton's engagement with music began during his teen years in Newark and Plainfield, New Jersey. He formed a doo-wop group, The Parliaments, in the mid-1950s. The group traveled to Detroit, where Clinton got hired as a songwriter for Motown Records. 1967 saw The Parliaments release a single through a Detroit-based label before they dropped the article and became singular. With the subtle name change to Parliament, the band would switch to a harder, more psychedelic sound, as heard on their debut album Osmium in 1970. Yet due to contractual complications, Clinton put Parliament on hold, rebranding the group "Funkadelic." A nomenclature shift provided creative freedom; or, to put it another way, economic constraint produced the collective structure that would become central to P-Funk mythology. Given the function renaming (Parliament to Funkadelic) played in escaping economic realities (contracts), it is unsurprising that wordplay in Clinton's lyrics play such an important role in the construction of P-Funk's mythology of spatial freedom-a desire for spatial freedom emerging at the end of the Great Migrations.

Clinton developed the P-Funk mythology throughout the 1970s, beginning with Funkadelic's 1970s self-titled album. While the nuances of the P-Funk mythos are outside the purview of this article, it might best be described as carnivalesque afrofuturism. Clones, aliens, spaceships, otherworldly gods, Funkateers, and wayward radio waves make up the cosmology, of which Clinton, as his alter ego Dr. Funkenstein, 
serves as the high priest. Central to this mythology is a desire-a demand-to dance and groove to fulfill one's true potential and to be "at one" with the cosmos.

The P-Funk mythos serves as a guide for the visuals and lyrics. Inspired by television cartoons, Clinton decided to have the bands dress in costumes made of shiny metallic fabrics, wigs, diapers, and fur. These costumes can be seen during live performances, in videos, and on Parliament's album covers. Notably, for Mothership Connection's cover, Clinton, dressed as Dr. Funkenstein, jumps out of a spaceship, a prop that also accompanied them on tour (fig. 1). Starting with Funkadelic's fifth album, released in 1973, Clinton enlisted Pedro Bell to provide illustrations for the band's covers and liner notes (fig. 2). Bell's psychedelic, underground-comix-inspired surrealism blends images of hyper-sexualized women with robots, aliens, and astronauts. P-Funk album art visualizes the imaginary spatial freedom contained within the music. In P-Funk lyrics, Clinton persistently refers to the mythology. For instance, in "Mothership Connection (Star Child)," he sings, "Well, all right, Starchild, Citizens of the universe, recording angels, We have returned to claim the pyramids, Partying on the mothership." Through visuals and lyrics, Clinton creates a cosmology that evokes a spatial imaginary beyond the planet. 


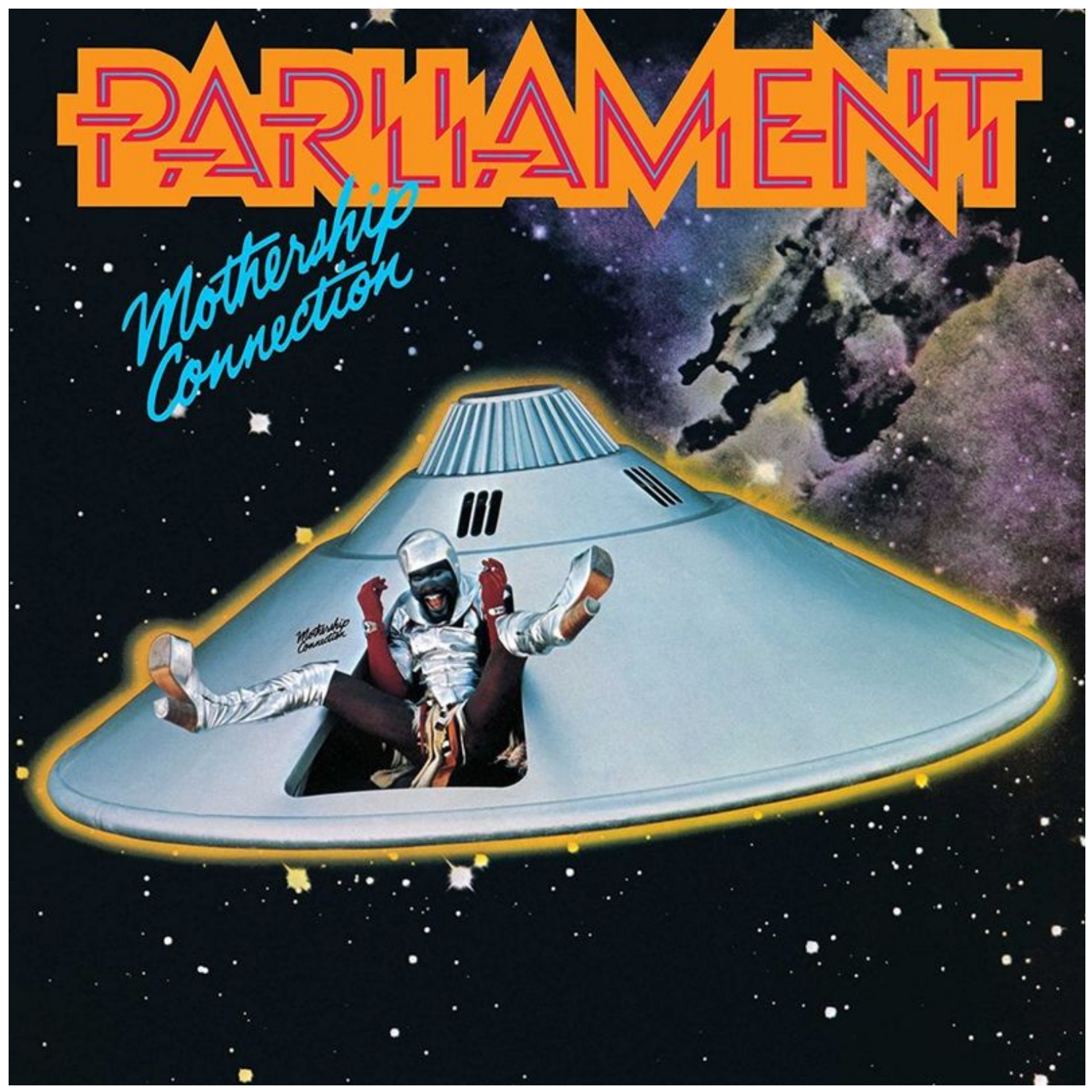

Figure 1: The cover of Mothership Connection. 


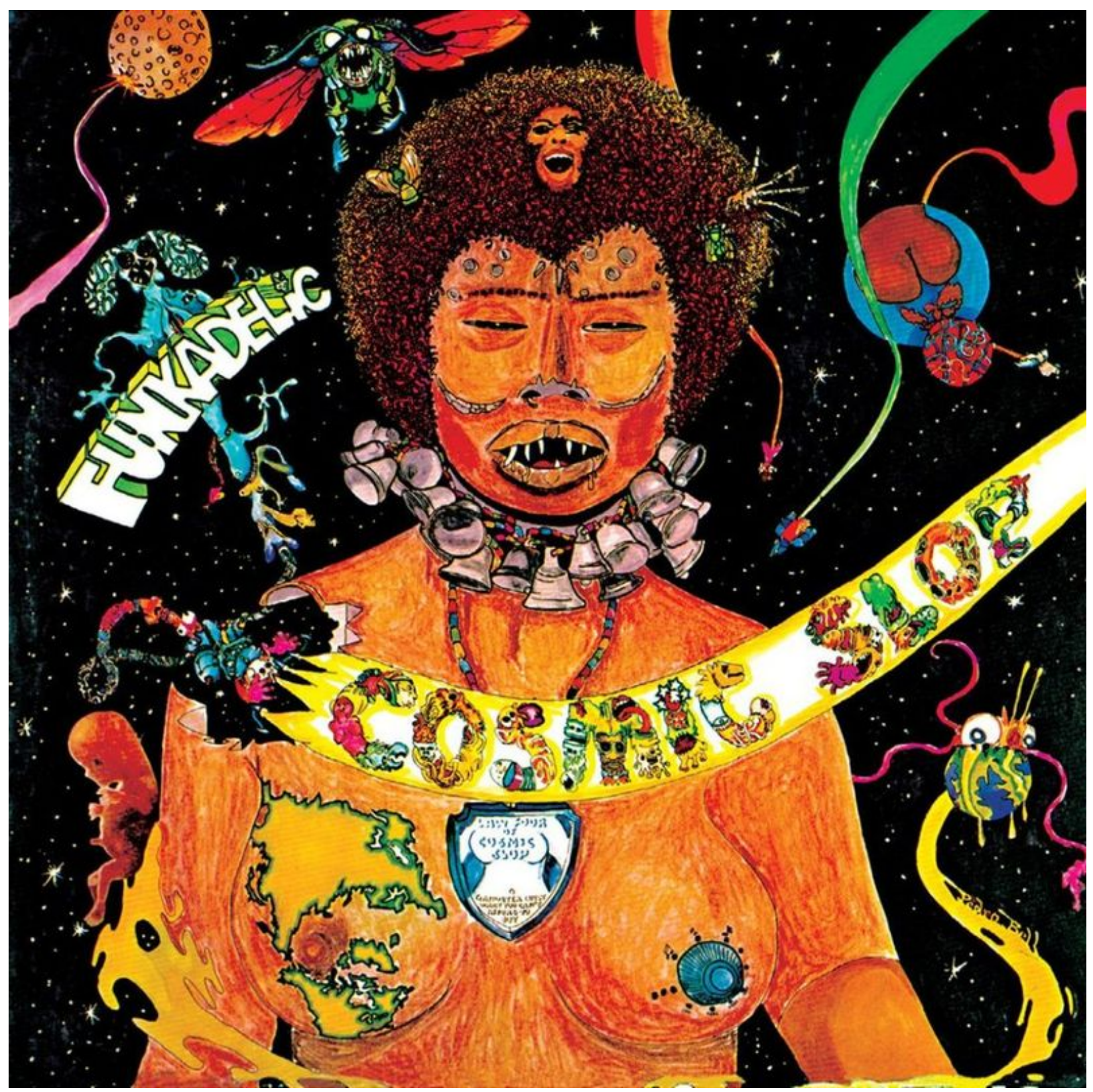

Figure 2: Cosmic Slop_Pedro Bell's first Funkadelic album cover.

While P-Funk lyrics provide an articulation of freedom and movement at the level of narrative or story, they also often produce a sense of freedom and movement at the sematic level. In line with the Black literary production traced out by Henry Louis Gates Jr., Clinton frequently uses wordplay, punning, nonsense, slang, and neologisms to push against the meaning of words-a sort of freeing from the words' semantic function. $\underline{5}$ For instance, in "Sir Nose D'voidoffunk," he sings, "I am Sir Nose'd D’Voidoffunk, I have always been, Devoid of funk, I shall continue to be, Devoid of funk," or the general substitution of "fuck" with "funk": "We love to funk you" from 
"Dr. Funkenstein" being just one example. Clinton's sematic play creates a movement of meaning within the lyrics, an imaginative and aesthetic kinesis. Clinton explicitly acknowledges and connects this practice of wordplay to contemporary urban centers and prior Black musical genres. In his autobiography, Clinton writes:

Most of all, that kind of punning was in keeping with the temper of the times: slang was increasingly popular because of drugs and Black Power and inner-city talk...the stars of the early seventies took it in another direction. Listening to Sly Stone was like taking a master class in brilliant nonsense...Sly, of course, was building on an old tradition of hepcats and jazz speak, going all the way back to Cab Calloway and continuing through Lord Buckley, but was doing it in the early seventies, when Black America was onstage in a different way. $\underline{6}$

Wordplay provided Clinton a lyrical freedom that made his P-Funk mythology seem far out, while still being in tune with historical practices of Black cultural production, with Black life.

Like referencing practices of Black cultural production to create a sense of kinetic freedom, Clinton would also directly reference prior Black cultural forms and use them to instantiate spatial and kinetic relationships. For instance, in "One Nation Under a Groove" (apocryphally conceived in Washington D.C. and recorded in Detroit, Michigan at United Sound in 1977-1978), the lyrics link the song to Black music and theatrical performances. Indeed, the song opens with a nested reference to Black American musical tradition, namely spirituals and soul music. "One Nation Under A Groove” begins:

So wide you can't get around it

So low you can't get under it

So low you can't get under it

So high you can't get over it

So high you can't get over it

This is a secularized interpolation of the spiritual "So High," whose lyrics read "My God is so high, you can't get over Him, He's so low, you can't get under Him, He's do wide, you can't get around Him." The Temptations used the structure of "So High" on their 1969 psychedelic soul single, "Psychedelic Shack": "They got music so high you can't get over it, So low you can't get under it." Funkadelic riffs on Black musical history. The "it" of the "One Nation Under a Groove" remains undefined just an "it" that is wide, low, and high. Here, the phrase takes on an indeterminate spatial quality. 
After this dense cultural reference and spatial block, "One Nation Under A Groove” explicitly references dance as a way of freeing oneself. A talking prelude states, "This is a chance, This is a chance, To dance your way, Out of your constrictions, Tell suckah!" Then the verse echoes these words and sentiment:

Here's a chance to dance our way

Out of our constrictions

Gonna be freakin'

Up and down

Hang-up alley way

With the groove our only guide

We shall all be moved

Ready or not here we come

Getting' down on

The one which we believe in

One nation under a groove

Getting' down just for the funk

Can I get it on the good foot

Getting' down just for the funk of it

Good God

'bout time I got down one time

One nation and we're on the move

Nothin' can stop us now

Ah ah aye ay ay

The lyrics do not only offer dancing as a way to freedom; the music of the song demands dancing. The groove is predominately made up of synth bass and drums. Bernie Worrell's synth bass part drives the song while producing otherworldly textures and vamping chords of synthetic brass. Worrell's synth sounds were a defining feature of P-Funk. The kick of the drums follows the rhythm of the bass, while syncopated cymbal bell and tom hits round out the percussion. The guitar hangs out on the right side of the track. The song would be Funkadelic's first number-one hit, spreading the collective's message of freedom through dance. Reinforcing this message of movement as freedom, in different stanza of the verse, Clinton sings, "Feet don't fail me now." This phrase has its roots in Black comedic and mistral performance of the earlytwentieth century. Like his use of wordplay, Clinton's referencing to Black cultural production dilates the historicity of P-Funk's songs while simultaneously vectoring such references towards funk's kinetic focus. The historicity that emerges from 
Clinton's lyrics allows us to read this mythos as responding to Black life at the end of the Great Migrations.

The titular single from Cosmic Slop would specifically address Black urban life, while still drawing on notions of dancing and otherworldliness. Indeed, this fusion takes place around the figure of a Black woman and the commodified circulation of her sexuality. "Cosmic Slop" tells, from her eldest child's perspective, the story of an urban mother who engages in prostitution in order to take care of her five children. Here, the circulation of the Black woman's body to meet the demands of urban poverty are not cast as a moral failure on her part but rather a necessary means to meet the demands of her constrictive economic conditions. Notably, the act of prostitution, the sale of her body for economic relief, is articulated in the lyrics:

Then the devil sang:

Would you like to dance with me?

We're doing the cosmic slop

Would you like to dance with me?

We're doing the cosmic slop

Would you like to dance with me?

We're doing the cosmic slop

Prostitution as devil's dance and cosmic slop codes the commodified circulation of the Black woman's body with an irreality that provides imaginative spatial freedom from the harsh realities of the ghetto- "She was well known through the ghettos, Tricks would come and then they go, The neighbors would talk and call her Jezebel." In "Cosmic Slop," imaginative spatial freedom becomes articulated in the song through the circulation of the Black woman's body, which is how she contends with the economic reality of the ghetto.

Towards the end of the 1970s, Clinton put together The Brides of Funkenstein, a women-fronted P-Funk group. Singers Dawn Silva and Lynn Mabry, who were originally singers with Sly and the Family Stone and joined Clinton's musical project in the mid-1970s, headed the band. Puns, female sexuality, and overt reference to funk music coalesce in outer space to make an aesthetic of movement heard in women voices. For instance, on the track "War Ship Touchante," Silva and Mabry sing

War ship Touchante

You have invaded the domain of the protectors.

Do not move 
You have violated the rhythmic movements of times and spaces.

You are hereby under mental and physical arrest.

And you are hereby in contempt of funk

Say brothers, you're required to dance the dance of sensitivity, you know?

Handle it

Dance Touchante

Wouldn't you like to dance with me closer, wouldn't you sir?

The ultimatum, the ultimate ultimatum, is to funk or walk!

May we board you?

I don't think you heard me.

May we board you?

Dancing, dancing, dancing, dancing

Lyrically, the song blends science fiction with childish sexual puns-"may we board you." In outer space, it is about dancing closely-touchante. Reinforcing the sciencefiction feel of the song is the heavy use of synthesizers, played by Worrell. Worrell's synths are some of the finest on "War Ship Touchante." He uses them to create the scene of the song. For instance, as the war ships are invading, Worrell produces a sonic texture of zapping laser sounds. Twinkling sample-and-hold-filter bleeps fill the background of the song, echoing an image of outer space, and pulsing synthetic sounds parallel the bass and vocals, while a brass sound comes in and out. While extremely musical, Worrell's work on the song is like a soundscape, a musical texture. This futuristic soundscape provides the musical background for Silva and Mabry's singing about sex and dancing. Like "Cosmic Slop," Black women's sexuality is used to articulate freedom, that is, a kinetic freedom through funk.

If the world is a ghetto, then it is no wonder that Clinton's P-Funk persistently turned towards the cosmic, surreal, and far-out. In doing so, P-Funk forcefully demonstrates within the genre of funk a desire for movement, so much so that it was willing to leave the Earth. And when P-Funk did come back to Earth, it offered a message of freedom and movement through funk. To articulate this message, lyrics would often turn to the figure of the Black woman and the circulation of her sexuality. P-Funk's cosmic mythology heightens and makes clear funk's investment in movement, particularly as it relates to Black women and their sexuality. But other funk bands stayed on earth and produced an aesthetic of movement against dwindling social and economic mobility. $\underline{7}$ 


\section{The Geography of Migration}

While Dr. Funkenstein and his fellow funkateers traveled the cosmos promoting funk and battling the forces of Sir Nose D’Voidoffunk, George Clinton's childhood movement from Kannapolis, North Carolina to New Jersey, where he formed The Parliaments, to Detroit, where he found musical success, is emblematic of larger migratory patterns of Black populations within the United States during the Great Migrations. Indeed, many of the funk's greats moved out of the South as children, either to Northern or West Coast cities. Sly Stone and Larry Graham of Sly and the Family Stone moved from Texas to San Francisco; Maurice White of Earth, Wind, \& Fire from Memphis to Chicago; Robert Ward of The Ohio Players from Luthersville, Georgia to Dayton, Ohio; and Betty Mabry Davis from Durham, North Carolina to Pittsburgh then onto New York City. This is neither to say that funk musicians were not originally from Northern cities nor that funk bands did not emerge in the South. The Isley Brothers were Cincinnati natives; most of The Ohio Players were Ohioans; Chicago natives rounded out Earth, Wind, \& Fire; and The Bar-Kays were from Memphis, originally forming as a backing band for Otis Redding. But at risk of stating the obvious, the Great Migrations brought constellation of musicians together that might not have happened otherwise.

The movements of these musicians and their families index the larger migration patterns of the movement of Black people during the Great Migrations. This migration has had a lasting effect on the demographic make-up of various regions of the United States. For instance, in 1900, 90\% of the Black population lived in the South; by 1960 it was $60 \%$; and by $1970,53 \% . \underline{8}$ This migration of Black people is often divided into two different periods: the Great Migration and the Second Great Migration. While both Migrations saw Black people leaving the South in staggering numbers, there are key distinctions between them. The first Migration, dated from 1916 to 1940, largely saw Black people leave rural areas for northern and midwestern cities: New York City, Chicago, Detroit, and Philadelphia. The second migration, which dates from 1940 to 1970, saw Black people migrating to West Coast cities: Seattle, Portland, San Francisco, Oakland, and Los Angeles. Urban-to-urban migration was more common during this period, though large percentages still came from nonmetropolitan areas. Indeed, migration to an urban setting defines these decades of travel, for as Black people shifted north and west, they also shifted from a predominantly rural to urban population: $22 \%$ urban in $1900,64 \%$ in 1960 , and $77 \%$ in $1970 . \underline{9}$

The Black population who had moved to the North and West prior to the 1950s was by and large met with a beneficial labor market, one in search of workers, but during the 
1950s jobs in non-Southern states began to decline. 10 Over the 1950s and 1960s, Black Americans traveling north and west did not find the same abundant job markets of the war years. Urban centers that once promised economic opportunity and freedom were now becoming places of economic stagnation and limited social mobility.

Black Americans were confronted by a rearrangement of labor in the US. Automation lessened the demand for factory and manufacturing jobs, blue-collar jobs decreased as white-collar and service-industry jobs boomed, and the expansion of the highway system drew businesses, jobs, and revenue out of cities into the suburbs, which were growing and facilitating White flight. Automation and the expansion of the transportation system left Black populations under- and unemployed. Indeed, this period saw the unemployment of Black men nearly double relative to their White counterparts. All of these factors affected the economic prosperity of Black urban communities.

Furthermore, through racist zoning practices, the construction of the highway system not only damaged cities economically; it also carved up and displaced Black communities. The vast circulatory system being built in the postwar period became a key factor in the constriction of Black American life during that time. What was being sold in the White US imagination as an avenue to more free time, more spatial freedom, and overall greater family bliss was, for large groups of Black Americans, a further social and spatial constraint. The postwar construction of radial highways damaged urban Black neighborhoods, as enumerated by Joseph DiMento and Cliff Ellis in Changing Lanes: Visions and Histories of Urban Highways. Highways expedited suburbanization, which promoted segregation; they disposed and displaced Black people from their communities, motivating moves into public housing; and they damaged Black social life through what DiMento and Ellis call "non-construction costs": noise, pollution, and making the city difficult to traverse by carving it up. $\frac{11}{\text { For }}$ instance, in Detroit-the home of Motown, where many funk artists would get their start-Black life in the city was drastically altered by the construction of the OaklandHastings Freeway, which began its planning stages in the late 1940s. This new highway predominately ran through Black neighborhoods on the city's Lower Eastside. The construction of this highway, along with others that divided up the lower side of Detroit, devastated businesses and the local economy and displaced Black people. Such displacement of populations and the reduction of available housing further cramped urban environments. Detroit was not alone: Similar practices happened in New York City, Syracuse, and Miami. As the postwar years progressed, declining labor 
markets and racist urban planning damaged Black life in cities. Social, economic, and, indeed, spatial movement was winding down.

The Great Migrations meant something different to Black men and Black women. The early years of the great migration saw more men than women moving, a discrepancy indexed in the women's blues music of the 1920s that Hazel Carby charts in "The Sexual Politics of the Woman's Blues." 12 Yet Black women did participate at every stage of the migration. During the early years of the Great Migrations, Black women predominately found employment as domestic servants and laundresses. With the onset of World War I, some of Black women found employment in industry. For instance, in Chicago in 1919, 12.6 percent of Black women were employed in factories. $\underline{13}$ Sometimes this employment would be a downgrade in professional status. Black women who were, for example, teachers in the South could not find similar employment in the North and would have to turn to domestic and factory work. Education and professional experience received in the South did not translate into economic opportunity in the North. However, in the postwar years, Black women's job prospects expanded into service and sales, and the civil rights movement of the 1960s opened up more opportunities in clerical work, which had been the domain of White women. By the waning years of the Great Migrations, Black women began to occupy more socially and culturally respected jobs than Black men. It is unsurprising that Black women would become the visage of mobility.

Interestingly, migration remained part of Black women's-and Black men's-economic mobility. At the beginning of the Great Migrations, Southern Black men and women migrating north faired economically better than their Northern counterparts. This trend persisted throughout the migrations. But by the end of the Great Migrations, Black northerners would often be the children and grandchildren of Black migrants of earlier moments, and compared to contemporary Black migrants, Black northerners were more frequently on welfare and suffered from unemployment at a far greater rate. Economic opportunity wears away generationally; movement-physical, spatial movement-was the key to economic opportunity. When the Great Migrations began winding down, so too did economic opportunity. $\underline{14}$ Like the blues before, funk registers the socioeconomic place of Black women, who were fully within urban spaces, a place lyrically represented within the funk genre. Black women's circulation within these spaces became one way that funk lyrically reflected and created movement in the songs of the genre. 


\section{Get Down}

Funk's movement is neither the movement of migration, of trains leaving the South, nor the spiritual and moral transcendence of soul, the sound of the civil rights movement. It is the movement to groove and to otherwise get down. Funk calls for dancing with clear connotations of sexual pleasure and satisfaction. This might be best exemplified by Kool \& the Gang's 1981 single “Get Down on It." Indeed, even for all of P-Funk's space travel, its central tenet was to funk. Instantiating movement within the lyrics and resonating with sex and sexual pleasure, it is unsurprising that funk songs providing stories of Black women's experience in urban locale would focus on the trope of the streetwalker. Funk expresses fantasies of movement for women that turn on the commodified circulation of sexualized bodies.

Against the social backdrop of the Great Migrations ending, endless funk songs command the listener to move. Lyrics reflect the energy of the rhythm and tone of the music. The timbral flavor of the genre should not be discounted in its creation of a feeling of movement. Like Worrell's synths that create the otherworldly sound of PFunk, music technologies were instrumental in creating funk's aesthetic of movement. The genre made good use of then emerging technologies: synthesizers, processing effects, and active pick-ups. For instance, guitarist would use a "wah-wah" effect that would rhythmically filter out treble frequencies of the instrument. An iconic example of this is the guitar in "Theme for Shaft," written by Isaac Hayes for Gordon Parks's 1971 movie Shaft. Furthermore, funk bands were often larger groups consisting of seasoned session musicians, echoing not only the arrangement of musicians in soul music but also jazz and swing, popular Black musical expressions of early-twentieth-century urban centers. While not wanting to diminish the ways in which technologies circulate, funk's production and instrumentation inflects an urban setting by the use of expensive music technologies associated with large studios and record companies.

Two funk songs released in 1974, The Ohio Players' "Skin Tight" and Labelle's "Lady Marmalade," clearly articulate this relationship between urban space, sexuality, and economics. While sexual pleasure was an explicit aspect of funk aesthetics, The Ohio Players were possibly the most sexual in their music and accompanying imagery. For instance, the cover of the album Skin Tight, which houses the single, features a side view of a woman on her knees only wearing tall leather boots. Her arms extended with her hands grasping her knees. Only her hands, forearms, and legs are visible (fig. 3). 


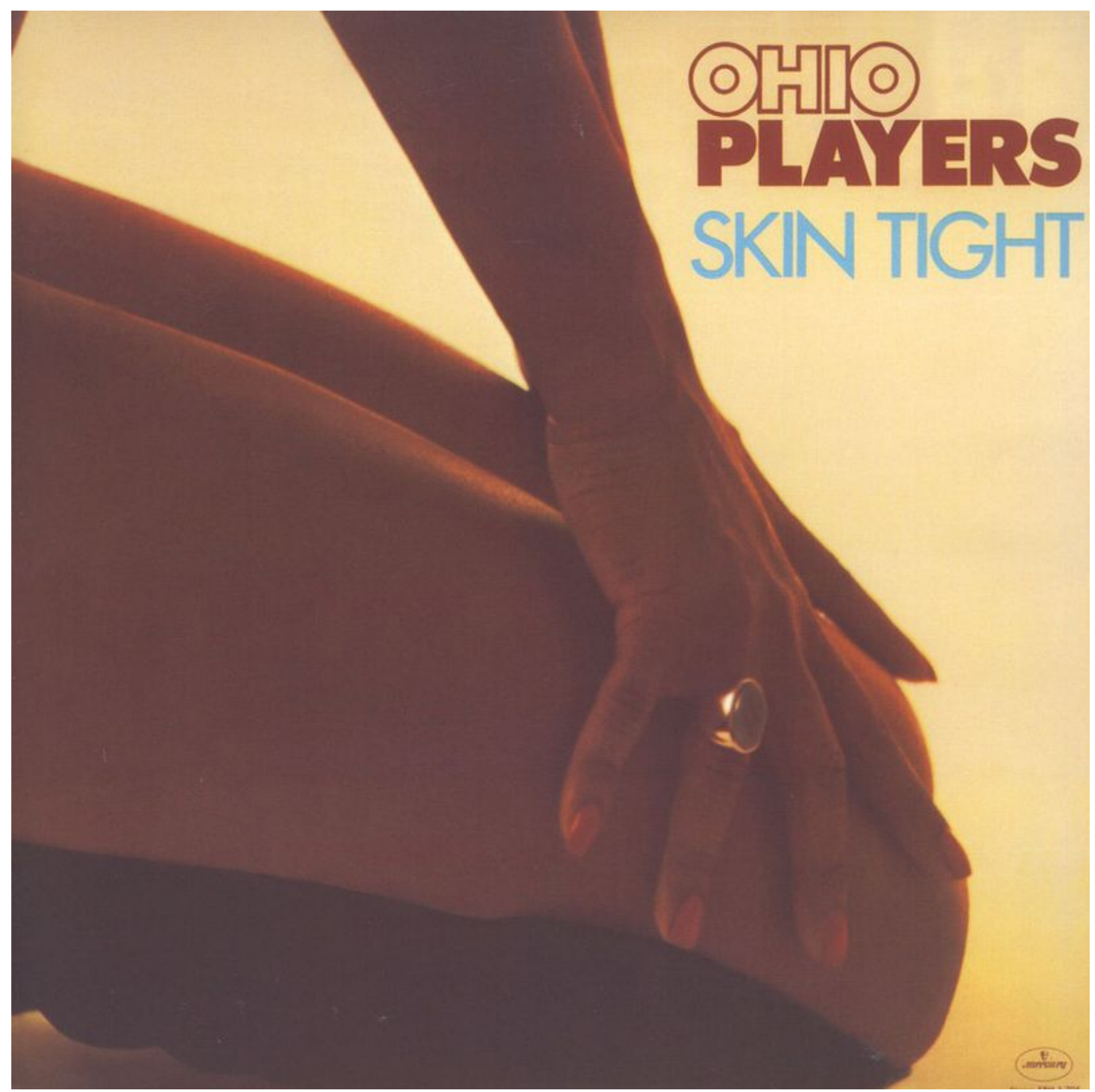

Figure 3: The cover of The Ohio Players' Skin Tight.

The back of the album shows the woman's booted feet and the side of her buttock. For how little clothing the woman on the album cover has on, the song "Skin Tight," as the name suggests, focuses on the clothing of a woman. The song opens with only the bass riff; a guitar, heavily processed by a filter envelope, comes in after an iteration of the bass part. The guitar parallels the bass. An ensemble of brass climbs in staccato bursts, and over this instrumentation, Leroy "Sugarfoot" Bonner releases wows, yeahs, and grunts before delivering a sexually implicit verse that details a woman and her clothes: 
You are a bad, bad missus

In them skin tight britches

Runnin' folks into ditches

Baby you're about to bust the stitches, yeah

The same groove continues, and the chorus clears any doubt about the theme of the song.

Skin tight

(Skin tight)

Wow, skin tight

(Skin tight, skin tight)

Go on, go on, go on

A brief horn-driven interlude, and then we return to the verse.

You are a real fine lady

Though your walk's a little shady

Step on the strip on time

There's money you're bound to find, yeah

This verse explicitly links this sexuality to an urban setting and economics. With her shady walk and search for money, the song reveals that the scantily clad woman is a prostitute. Furthermore, we now know she is on the strip. The Dayton-based band is most likely referring to Dayton's strip of West 5th, a center of Black urban life, yet this locale resonates with the geographic structure of most urban centers, the term "strip" denoting a generic space of a major road, lined by businesses, that leaves and enters a city. $\underline{15}$ The streetwalker circulates on a major artery of urban life.

Like The Ohio Players' “Skin Tight," Labelle's 1974 hit sensation “Lady Marmalade,” written by Kenny Nolan and Bob Crewe, also explicitly linked sex, urban environments, economics to the circulation of Black women's bodies. Patti Labelle belts:

He met Marmalade down in old New Orleans

Struttin' her stuff on the street

She said "Hello,

Hey Joe, you wanna give it a go?”

Itchi gitchi ya ya da da

Itchi gitchi ya ya here

Mocha-choca-lata ya ya 
Creole Lady Marmalade

Voulez-vous coucher avec moi ce soir?

Voulez-vous coucher avec moi?

Labelle's singing excites vitality and sexual energy. The song charts a prostitute's proposition, to the sexual rendezvous, to the man's memory of the encounter. Labelle singing of a streetwalker in New Orleans is one of the rare instances a Southern city is mentioned. This exception of spatial marking in a funk single might be accounted for by the ways in which New Orleans functions in the US imaginary as a raced, multiethnic space as well as one known for vice. "Lady Marmalade" takes on racialized coding-“Mocha-choca-lata ya ya” and more explicitly, "Touching her skin feelin' silky smooth, The color of café au lait." "Skin Tight" and "Lady Marmalade" fixate-skin and clothing-on the figure of the Black woman as prostitute. The women of these songs circulate through the street for the purpose of selling their bodies. The energetic music of funk supports narratives of prostitutes navigating urban spaces.

Where Parliament's and Funkadelic's album covers articulated P-Funk's cosmic mythology and The Ohio Players' covers expressed their focus on sexual pleasure, the album cover for Nightbirds, the LP that contains "Lady Marmalade," visualizes the kinetic energy of funk. The cover is a collage of Patti Labelle, Nona Hendryx, and Sarah Dash. The women are captured as blurs of movement through the overlay of multiple exposures. Their dresses become smears of color-blue, yellow, orangepunctuated by glints of shining fabric and jewelry (fig. 4). A shimmering 1970s update on Marey, the photographic album cover visually articulates the movement of funk music, a capturing of its kinetic dynamism. 


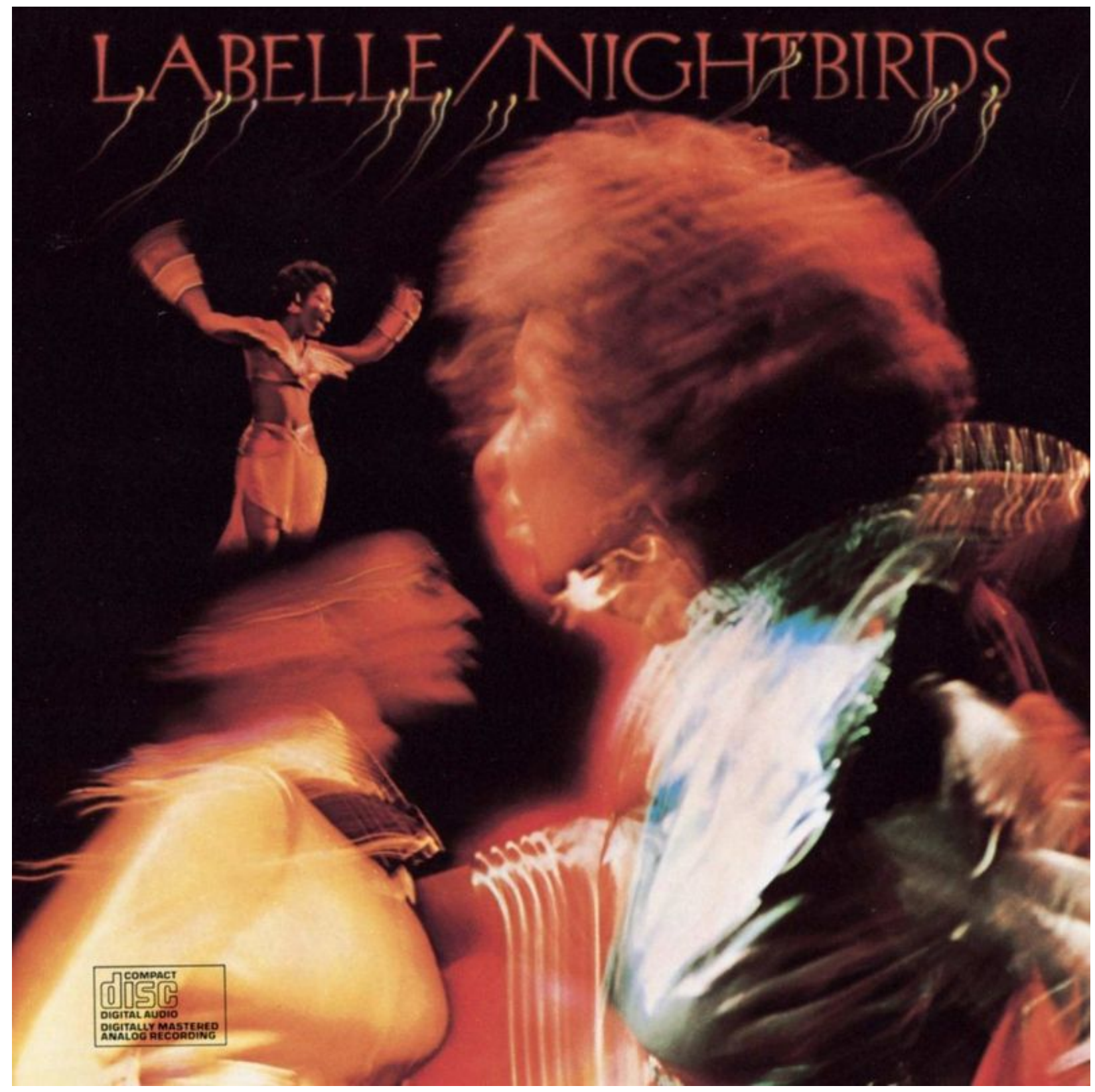

Figure 4: The cover of Patti Labelle's Nightbirds

The prostitute was not the sole method for expressing a fantasy of movement through the Black woman's body. For instance, an early funk/soul hybrid single by The Honey Cones expressed the circulation of the Black woman's body for sale through the figure of a newspaper's want ads, which provides the song with its title. Released in 1969, "Want Ads" articulates a gender and sexual politics similar to that traced by Hazel Carby in "The Sexual Politics of Woman's Blues" and grounds it in an urban environment. Written by Greg Perry, General Norman Johnson and Barney Perkins, the song conveys a woman's desire for a new partner. The song begins with a call-response 
between the Edna Wright, Shellie Clark, and Carolyn Willis's vocals and the guitar. The trio sings "wanted," then a swift up and down stroke of G\#, and then the singing returns with "young man, single and free," then an up and down stroke of C\# and punctuated set of three down strokes, then the vocals continue "Experience in love preferred," and now guitar and vocals go together as the line finishes with "but will accept a young trainee." This alternating structure creates a tension that is finally release then the vocals and guitar come together. As the song continues, we learn that the woman of the song's desire for a man stems from dissatisfaction with the man she's got. This dissatisfaction is cast in terms of the man leaving the domestic space.

At home I find myself, lost and all alone

My man is playing the field, the thrill is gone

He stays out all night, says he's with the boys

But lipstick on his collar, perfume on it too

Tells me he's been lying, tell ya what I'm gonna do

I'm gonna put it in the want ads, this girl's in misery

Gonna put it in the want ads, somebody rescue me

I spend my nights alone, cryin' bitter tears

Although I cry aloud, nobody really hears

And when I need him most, he's never by my side

He's either playing cards, or drinking at the bar

He thinks that I'm a fool, I'm going to the evening news

Underneath the vocals, a prominent bass line walks and punctuates the rhythm and melody of the vocal line. Guitar, brass, and strings provide support. The music and vocal delivery of the singers create a jubilation of freedom, and this energy builds towards the chorus, where the protagonist asserts herself. The woman does not sit around, but rather, turns to the media of the public sphere-the newspaper and television-to solve her domestic problems and sexual/romantic dissatisfaction.

Gonna put it in the want ads, I need somebody new

Gonna put it in the want ads, my man and I are through

Extra extra, read all about it, wanted, young man single and free

Experience in love preferred, but will accept a young trainee

The want ads of the newspaper provide an avenue for the woman to seek romantic and domestic satisfaction. She turns towards the public sphere instead of the domestic (a point reinforced by "going to the evening news") to pursue satisfaction, and the 
section of the newspaper she turns to is directly concerned with economics, the want ads. The woman circulates herself through the form of the newspaper.

At the moment when migration and Black people's movement to urban centers for economic opportunity and freedom were winding down, funk became a defining feature of Black cultural production. From the late-1960s through the 1970s, funk became a mode of mediating the experience of Black urban life, one marked by economic and social stagnation. Central to this mediation was a displacement of movement from the social and economic realm to aesthetics. Different funk artists' lyrics, music, and imagery worked towards creating an aesthetic of movement, a feeling of kinesis that was being drained from the lives of large swaths of the US urban Black population. Funk maps out a complex aesthetic and imaginative movement-one that would travel to outer space and inner cities throughout the US. Throughout all these spaces, the Black woman and her sexuality would circulate; she would become a figure through which funk would articulate its aesthetic of movement at a time when social and economic mobility was winding down.

\section{Footnotes}

1. Hazel V. Carby, "Policing the Black Woman's Body in an Urban Context," in Cultures in Babylon: Black Britain and African American (New York: Verso, 1999), 23.

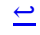

2. For instance, in his canonical history of funk music, a canonicity reinforced by a forward by George Clinton, Rickey Vincent reflects on the funk aesthetic, characterizing funk as an "aesthetic...of uninhibited, soulful behavior that remains viable because of a faith in instinct, joy of self, and a joy of life, particularly unassimilated Black American life." Rickey Vincent, Funk: The Music, the People, and the Rhythm of the One (New York: St. Martin's Griffin, 1996), 4. Funk, for Vincent, is an aesthetic of uninhibited instinct. Similarly, Toni Morrison's use of funk in The Bluest Eye, notes Madhu Dubey, "evokes funk to figure a natural racial identity repressed in urban society" Madhu Dubey, Signs and Cities: Black Literary Postmodernism (Chicago: University of Chicago Press, 2003). These are just two instances that triangulate Blackness, authenticity, and the aesthetic of funk. $\boxminus$ 3. Tony Bolden, "Theorizing the Funk: An Introduction," in The Funk Era and Beyond New Perspectives on Black Popular Culture, ed. Tony Bolden (New York: Palgrave, 2016), 15. 
4. Joshua Clover, 1989: Bob Dylan Didn't Have This to Sing About (Berkeley: University of California Press, 2009). $\_$

5. For an analysis of Clinton's signifying politics, see Ted Friedman, "Making it Funky: The Signifyin(g) Politics of George Clinton's Parliafunkadelicment Thang," unpublished work-in-progress paper, 1993, https://www.academia.edu/2811336/Making_It_Funky The Signifyin_g_Politics_of_Ge orge Clintons Parliafunkadelic $\triangleq$

6. George Clinton, Brothas Be, Yo Like George, Ain't That Funk' Kinda Hard On You? (New York: Atria, 2014) 111.

7. Earth, Wind, \& Fire are a clear exception to this. $\triangleq$

8. Sam Joseph Dennis, African-American Exodus and White Migration, 1950-1970: A Comparative Analysis of Population Movements and Their Relations to Labor and Race Relations (New York: Garland Publishing, Inc., 1989), 18, 93, 121; Marcus E, Jones, Black Migration in the United States with Emphasis on Selected Central Cities (Saratoga: Century Twenty One Pub., 1980), 38-89. $\_$

9. Jones, Black Migration, 38-89.

10. There was a brief stagnation of labor in 1930s. $\_$

11. Joseph F. DiMento and Cliff Ellis, Changing Lanes: Visions and Histories of Urban Freeways (Cambridge: MIT Press, 2013), 126.

12. Hazel V. Carby, "The Sexual Politics of the Woman's Blues," in Cultures in Babylon: Black Britain and African American (New York: Verso, 1999). 13. James R. Grossman, Land of Hope: Chicago, Black Southerners, and the Great Migration (Chicago: University of Chicago Press, 1989), 184.

14. For instance, by the mid-1970s, Black men were earning over 70 percent of the wage that White men were earning, a substantial increase compared to prior decades. Yet from 1970 onward, such economic growth for Black men has not been the same. From 1970 to 2000, Black men's wages rose in relationship to White men in most Urban centers of the US (notably, this was not the case for Chicago, Detroit, and Philadelphia, key Urban centers of Black migration), but Black men's annual salary decreased in relationship to White men's salaries (again, notably, only Memphis, Atlanta, New Orleans, Washington D.C., and Baltimore saw Black men's 
salaries marginally close the annual salary gap). Clearly, post-Great Migrations, the North and West no longer promised the same economic mobility. Natalia A. Kolesnikova and Yang Liu, "A Bleak 30 Years for Black Men: Economic Progress Was Slim in Urban America," Federal Reserve Bank of St. Louis, July 1, 2010, https://www.stlouisfed.org/publications/regional-economist/july-2010/a-bleak-30years-for-black-men-economic-progress-was-slim-in-urban-america..

15. For more on The Ohio Players and the spatial politics of their music, see Scot Brown, "A Land of Funk: Dayton, Ohio," in The Funk Era and Beyond New Perspectives on Black Popular Culture, ed. Tony Bolden (New York: Palgrave, 2016) 